\title{
10 health stories that mattered: Mar. 3-7
}

- The current shortage of various dosages of Ritalin and its generic equivalent has prompted the Canadian Medical Association and the Quebec Order of Pharmacists to demand that shortage alerts be mandatory. The two groups also want a list of 400 essential medicines that manufacturers would have to maintain in a three-to-sixmonth reserve.

- Only $60 \%$ of treatments for rare disorders are available to Canadians, and market approval can take up to six years longer than in Europe or the United States, states a petition by the Canadian Organization for Rare Disorders (CORD) to create an orphan drug regulatory framework for Canada. There are about three million Canadians with rare disorders, according to CORD.

- Telus Health is poised to become Canada's largest electronic medical record (EMR) provider. This week, it acquired Med Access Inc., a company that provided EMRs to 2000 physicians in British Columbia, Alberta, Saskatchewan, Manitoba and Ontario. Last year, Telus Health acquired the EMR business once operated by MD Practice Software LP, a member of the MD Physician Services Group and a subsidiary of the Canadian Medical Association.

- Gluten-free, allergy-conscious food is the top trend in Canadian restaurants, states the 2014 Chef Survey by Restaurants Canada. "The Canadian diner has a heightened awareness of food intolerances, allergies and ingre- dients, and chefs are taking note," Garth Whyte, Restaurants Canada president and CEO, said in a press release. "We've been keeping an eye on this trend, and created a restaurant-focused food allergy guide to help our members cater to customers' diverse needs in a safe environment."

- Ontario is adding 75 nurse practitioners to long-term care facilities over the next three years, announced the province's Ministry of Health and Long-Term Care. The government suggests this will help prevent injuries from falls, improve the resident experience and reduce unnecessary ambulance use, emergency department transfers, use of restraints and hospital admissions.

- Illegal medical marijuana dispensaries will not be shut down in Vancouver, British Columbia, when the new federal law limiting the production and sale of medical marijuana to large, licensed growers comes into effect Apr. 1. "It really is about access to medication, and the rules under the new federal law would essentially block people from getting their medication," city councillor Kerry Jang told The Vancouver Sun. "We just don't see these dispensaries as something we need to shut down, as long as they are only providing marijuana to people who medically need it."

- According to a poll by Forum Research, $12 \%$ of Canadians say they are the primary caregiver for a patient with dementia. Most of these caregivers are older $(16 \%)$, the least wealthy (22\%) and among the least educated $(17 \%)$ of the 1824 Canadians polled. Quebec respondents were the most likely to say they looked after someone with dementia (18\%), followed by British Columbia (15\%).

- The New Brunswick Court of Appeal has given the green light to a class-action lawsuit against pathologist Dr. Rajgopal Menon and the Miramichi Regional Health Authority. The $2-1$ decision by the province's highest court overruled a lower-court decision. Menon was previously found to have made thousands of partial or full misdiagnoses between 1995 and 2007.

- Canada's largest integrated brain centre brings research and patient care together in Vancouver, British Columbia. The \$70-million Djavad Mowafaghian Centre for Brain Health includes clinics for multiple sclerosis, Parkinson disease and other brain disorders, as well as research labs in concussion, stroke, addiction and healthy aging. It purports to offer residents improved access to treatments and clinical trials.

- In the wake of several food safety scandals, the federal government is revising the Canadian Food Inspection Agency (CFIA) regulations. In the next few months, CFIA will seek input from industry and stakeholders on the draft regulations. The new regulations are slated to come into effect in 2015. - Roger Collier and Barbara Sibbald, CMAJ

CMAJ 2014. DOI:10.1503/cmaj.109-4755 